IZA DP No. 5047

Adolescent Drug Use and the Deterrent Effect of School-Imposed Penalties

Glen R. Waddell

July 2010 


\title{
Adolescent Drug Use and the Deterrent Effect of School-Imposed Penalties
}

\author{
Glen R. Waddell \\ University of Oregon \\ and IZA
}

\author{
Discussion Paper No. 5047 \\ July 2010
}

IZA

P.O. Box 7240

53072 Bonn

Germany

Phone: +49-228-3894-0

Fax: +49-228-3894-180

E-mail: iza@iza.org

\begin{abstract}
Any opinions expressed here are those of the author(s) and not those of IZA. Research published in this series may include views on policy, but the institute itself takes no institutional policy positions.

The Institute for the Study of Labor (IZA) in Bonn is a local and virtual international research center and a place of communication between science, politics and business. IZA is an independent nonprofit organization supported by Deutsche Post Foundation. The center is associated with the University of Bonn and offers a stimulating research environment through its international network, workshops and conferences, data service, project support, research visits and doctoral program. IZA engages in (i) original and internationally competitive research in all fields of labor economics, (ii) development of policy concepts, and (iii) dissemination of research results and concepts to the interested public.
\end{abstract}

IZA Discussion Papers often represent preliminary work and are circulated to encourage discussion. Citation of such a paper should account for its provisional character. A revised version may be available directly from the author. 
IZA Discussion Paper No. 5047

July 2010

\section{ABSTRACT}

\section{Adolescent Drug Use and the Deterrent Effect of School-Imposed Penalties}

Simple OLS estimates of the effect of school-imposed penalties for drug use on a student's consumption of marijuana are biased if both are determined by unobservable school or individual attributes. The potential reverse causality is also a challenge to retrieving estimates of the causal relationship, as the severity of school sanctions may simply reflect the need for more-severe sanctions. I offer an instrumental-variables approach to retrieving an estimate of the causal response of marijuana use to sanctions and thereby demonstrate the efficacy of school-imposed penalties as a deterrent to adolescent drug use. This is the first evidence of such efficacy and, given what is known about the consequences of drug use, suggests that school sanctions may have important long-run benefits.

JEL Classification: $\quad$ 12, K42

Keywords: drug, crime, adolescent, risky behavior, expulsion

Corresponding author:

Glen R. Waddell

Department of Economics

University of Oregon

Eugene, OR, 97403-1285

USA

E-mail: waddell@uoregon.edu

\footnotetext{
*I thank Jason Lindo, Joe Price, Larry Singell and seminar participants at the 2010 Western Economic Association International meetings. Any errors remain my responsibility.
} 


\section{Introduction}

There is a large literature that documents the long-run costs associated with drug use, and the implied gains to lowering adolescent drug use are not difficult to establish from existing research. For example, in an instrumental-variables design, DeSimone (2002) shows that employment probabilities are substantially reduced by marijuana and cocaine consumption. Considering the relationship between marijuana use in high school and future earnings, Ringel et al. (2006) add that a significant part of the negative relationship between substance use and earnings reflects an indirect mechanism by which early marijuana use affects human capital accumulation, which in turn affects earnings. The focus of this analysis is on the role of school policy in determining student's consumption of the most common illicit substance used by adolescents - marijuana.

Of course, the consequences of substance use are not restricted to labour-market outcomes. For example, Kaestner (1995) shows that drug users tend to delay marriage and, conditional on marriage, experience shorter marriage durations. Markowitz (2000) suggests that marijuana may also cause increased engagement in physical fights. Substance use has also been identified as a leading causal factor in suicidal thoughts and behaviours (Markowitz et al. (2002)). Clearly, there is the potential for a significant down side associated with adolescent drug use, which should motivate policy makers in their stewardship of adolescents.

Somewhat surprisingly, however, the role of school policy in a student's choice to consume drugs has largely been ignored in the economics literature. Yet, among the established results in the literature, there are several empirical patterns that raise particular concern around this shortcoming. For example, Chatterji (2006) also shows that marijuana use in high school is associated with lower levels of educational attainment, and concludes with an appropriate conjecture that "public policies that are effective in reducing substance use during high school should have some impact on educational attainment." Based on a relationship between marijuana use and lower high-school graduation rates, Yamada et al. (1998) also conclude with the suggestion that "high-school-based preventive programs which discourage alcohol consumption and marijuana use are highly recommended." The literature has also documented that the earlier one starts using a particular drug the less likely one is to stop using that drug (van Ours (2006)), which further supports considering the role of schools in influencing drug use. To the extent one believes that marijuana is a gateway to other (harder) substances, the benefits to curbing adolescent marijuana use also include mitigating this potential escalation and any costs associated with such escalation. ${ }^{1}$

In the end, the existing literature leaves us largely uninformed about the relationship between school policy and the substance use of youth. ${ }^{2}$ Yet, there is reason to consider

\footnotetext{
${ }^{1}$ Although, Bretteville-Jensen and Jacobi (2008) considers an alternative to a causal link between cannabis and subsequent hard-drug use, offering non-causal explanations for the observed "staircase" pattern.

${ }^{2}$ As an exception to the dearth of evidence on the role of institutions in drug use, although somewhat removed from the focus here, Mehay and Pacula (1999) exploits a drug-testing policy implemented by the military in 1981 and documents that rates of illicit-drug use among military personnel are significantly lower than civilian rates in years after the implementation of the program but not before, which they interpret as a sizable deterrence effect. Some 30 years have past since this policy change was initiated, though, and the nature of the policy change does not necessarily map into us learning about the implications of school policy toward drug use. Exploiting transaction-level data, Pacula et al. (2007) does find that changes in sanctions that lower the legal risks for users are associated with higher marijuana prices in the short-run. Anderson
} 
the influence of school policy in this regard, with elementary and secondary institutions well positioned to influence adolescent choices. ${ }^{3}$ Thus, the focus of this analysis is on the potential for school policy to influence a student's consumption of marijuana.

Specifically, I will model one's marijuana use as a function of the the penalty one's school would impose if one were to be caught consuming an illegal drug. In proceeding toward a preferred specification, I will be transparent about the empirical regularities in the data and report simple OLS specifications that highlight the endogeneity of penalties in such an environment. I will then adopt an instrumental-variables approach to retrieving an estimate of the causal influence of sanctions on student behaviour and, in the end, demonstrate the efficacy of school-imposed sanctions - stiffer sanctions for drug use cause students to be less likely to consume marijuana. In particular, the preferred estimates are identified off of variation in penalties imposed on second-time drug offenders across schools that issue the same penalties to first-time offenders, with the second-offence penalty instrumented for with measures of how much the school escalates its penalties for second-time offences (i.e., over first-time offenced) in non-drug areas of discipline.

In Section 2, I detail the data used in this analysis. In Section 3, I develop the empirical model and introduce the instrumental variables to be used to recover causal estimates of school-imposed penalties on marijuana use. I offer some discussion in Section 4 followed by concluding remarks in Section 5 .

\section{Data}

\section{$2.1 \quad$ Source}

For our purpose, the National Longitudinal Study of Adolescent Health is a particularly fitting collection of information on adolescent behaviors as it is designed to investigate adolescent health and risk behaviors. The "Add Health" project is widely considered to be the largest and most comprehensive survey of adolescents ever undertaken, with a stratified sample of 80 high schools collectively representative of the U.S. school system with respect to region of country, urbanicity, school size, school type, and ethnicity. For each of these schools, "feeder" schools were selected on the basis of student contributions to the chosen high school. An in-school questionnaire was administered to students in sampled schools between September 1994 and April 1995, and a random sample was selected from each of these schools for more detailed interviews, conducted in the respondents' homes between April and December 1995. It is this detailed "In-Home Survey" that is adopted in the current analysis. A total of 20,745 adolescents were interviewed for the Wave I In-Home Survey, although only 19,865 have school and grade identification. After dropping observations with missing values, the largest sample from which I report estimates is 17,016, or roughly 86 percent of

(2009) also offers some evidence that demand-side interventions to curbing drug use may be ineffective at changing consumption behavior, although this is focussed on methamphetamine use.

${ }^{3}$ In a related consideration, while the emphasis is more broadly on school crime (e.g., violent incidents), Cook et al. (2009) argues that crime in school is not a simple sum of students' criminal propensities - "that the organizational characteristics of the school have considerable influence." 
the Wave I sample. ${ }^{4}$ Summary statistics for this sample are shown in Table 1.

\subsection{Marijuana}

While marijuana has been the most popular illicit substance among youths for some 25 years, there has been some variation in usage rates across time. With the first wave of Add Health collected in 1994/5, one should note that 1992 is generally thought of as a low in adolescent marijuana use. Marijuana use again rose after $1992 .^{5}$

In the Add Health survey, the available information about marijuana use derives from responses to the question, "During the past 30 days, how many times did you use marijuana?" Roughly 14 percent of Add Health respondents report consuming marijuana in the 30 days prior to the interview. Given the mass at zero, I will report the results of a discretized version of this continuous response. For completeness, I will consider the intensive margin separately. Since I am relying on self-reported participation in potentially sensitive areas of disclosure, I note that for sensitive topics survey respondents listened to pre-recorded questions through earphones and entered their answers directly on laptops in order to maintain confidentiality and to minimize the potential for interviewer or parental influence. Rates of risky behaviors reported in Add Health are consistent with those measured in other sources (see Mocan and Tekin (2005), Mocan and Tekin (2006), and Mocan and Tekin (2010)).

\subsection{School-imposed penalties}

Add Health records the penalties associated with both the first and second occurrences of student drug use, which will enable the identification strategy adopted below. Specifically, school administrators report the consequence a student faces when he is caught "using an illegal drug at school" for the first time and, separately, caught a second time.

All Add Health schools deal with first-time offenders with either an in-school suspension, an out-of-school suspension, or an expulsion. Possibly given the seriousness of drug use in adolescents, there is a clustering of sorts in how schools penalize drug-related offences. For example, among the largest sample used here, only four schools (of 132) impose in-school suspensions to first-time offenders, while 78 schools issue out-of-school suspensions and 50 schools issue expulsions. Of the 82 schools that do not expel first-time offenders, 47 schools will expel students upon a second occurrence.

\section{Empirics}

Point estimates from a simple model of drug use on school-level penalties for drug-related offences will be subject to some interpretive challenges. In particular, to the extent schools respond to higher drug use with more-severe penalties, OLS estimates of this relationship will

\footnotetext{
${ }^{4}$ Results are robust to dropping juvenile arrests, arrests per crime, and median household income and keeping the observations for which these census variables (i.e., the largest source of missing information) are unavailable.

${ }^{5}$ Pacula et al. (2000) offer a nice analysis of this trend, linking time-series variation in consumption to changes in perceptions of the harms associated with regular marijuana use.
} 
be biased upward. In Section 3.2, I offer an instrumental-variables strategy through which I retrieve an estimate of the causal role of punishment severity on drug use. In motivating such a specification, I first present simple OLS models of the relationship in Section 3.1, and arrive at the sample of schools that will be used in identifying the causal estimate.

\subsection{A baseline specification}

Consider a general model of whether individual $i$ has consumed marijuana as a function of the penalty associated with school-related drug offences,

$$
\text { Marijuana }_{i g s}=\gamma_{g}+\beta_{1} \text { Penalty }_{s}^{\text {drugs }}+\gamma X_{i s}+\epsilon_{i g s},
$$

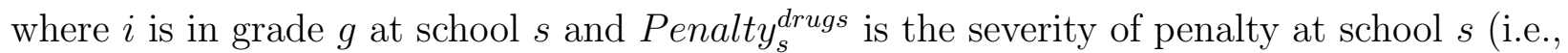
in-school suspension, out-of-school suspension, or expulsion).

Since penalties do not vary within schools, $\hat{\beta}_{1}$ will be identified by the variation in Penalty that exists across schools. Grade-level fixed effects $\left(\gamma_{g}\right)$ will be included throughout the analysis, so identification in all cases will be within grade-level, across schools. With no allowance for the inclusion of school-level fixed effects, I will control directly for the observable heterogeneity across schools with school size (i.e., small, medium, large), governance (i.e., public or private), urbanicity (i.e., urban, suburban, rural), and region (i.e., West, Midwest, South, Northeast). ${ }^{6}$ I will also include county-level information on juvenile arrests per capita, arrests per crime, median household income, the proportion urban, the proportion rural, and the unemployment rate. At the individual level, included in $X_{i s}$ will be indicator variables for gender, race (i.e., black, Asian, Hispanic, other nonwhite), parent education (i.e., lessthan high school, high school, some college, bachelor, graduate/professional), and religious participation (i.e., an indicator for weekly attendance). In all specifications I report standard errors that are corrected for clustering at the school level.

As a first pass, I report the estimated coefficients of a linear-probability model of the form (1), allowing level shifts in marijuana use with each first- and second-offence penalty observed in the data. ${ }^{7}$ Since schools vary in their penalties for first-time offenders by imposing inschool suspensions, out-of-school suspensions, or expulsions, I include intercept shifters for out-of-school-suspensions and expulsions. Since schools vary in second-offence penalties only between out-of-school suspensions or expulsions, I allow for a difference in marijuana use by whether student $i$ 's school expels students for second offences.

In Column (1) of Table 2, I cannot reject that any of these differences are zero - when uncorrected for endogeneity, there is no measurable difference in the reported marijuana use of students associated with their school's disciplinary response. This suggests that schools' drug-related penalties are ineffective in determining adolescent drug use. However, endogenous penalties imply that these estimates are biased upward. There are also no significant

\footnotetext{
${ }^{6}$ Although interesting, many other school-level attributes have insufficient variation to consider including as covariates. For example, greater than 98 percent of schools offer drug awareness and resistance education programs.

${ }^{7}$ Results are robust to alternatives to estimating linear probabilities. However, discrete-type IV estimators, which will be required in subsequent specifications, assume that the endogenous regressors are continuous and are not appropriate for use with discrete endogenous regressors. Thus, reporting linear probabilities here allows for better comparison to the subsequent two-stage least squares estimates.
} 
patterns in drug use revealed when first- and second-offence punishments are entered separately, as reported in columns (2) and (3).

\subsection{An instrumental-variables approach}

\subsubsection{IV setup}

In motivating the identification strategy below, one should have in mind an interpretation to the two penalties associated with drug use at a given school. One reasonable interpretation is that the penalty for a second occurrence captures what a school is ultimately prepared to do in response to this behaviour and that the first, to the extent that it is less severe, is some measure of grace being afforded to "first-time offenders." If on point at all, one would be particularly reluctant to consider the variation in first-offence punishment as exogenous to student behaviour, since this "grace" might well be earned (e.g., in response to less drug use).

In order to retrieve an estimate of the causal effect of penalty severity, I will consider the variation in second-offence penalties in a sample of schools with common first-offence penalties. The obvious payoff from this restriction is in keeping any unobserved heterogeneity that is motivating differences in first-offence penalties from contributing to the estimated effect of school-imposed penalties on drug use - of $\hat{\beta}_{1}$. In this environment, I will then instrument for each school's second-offence penalty. This is arguably the cleanest environment available for answering the question of interest and will ultimately serve as the preferred specification.

Given the breakdown of penalties, this amounts to restricting the sample of students to those that attend schools that issue out-of-school suspension to first-time offenders. In short, there are too few schools issuing in-school suspensions to reasonably interpret estimates from separate specification and there is no comparable specification for students who are at schools that treat first offences with expulsion, as their second-offence consequences are irrelevant. ${ }^{8}$ This highlights a tradeoff in the identification strategy - achieving cleaner identification by restricting the sample of schools by their first-offence penalties.

Conditional on being in such a school, then, I instrument for Expulsion drugs in a model of $i$ 's choice to consume marijuana,

$$
\text { Marijuana }_{i g s}=\gamma_{g}+\beta_{1} \text { Expulsion }_{s}^{\text {drugs }}+\gamma X_{i s}+\epsilon_{i g s},
$$

where again, $i$ is in grade $g$ at school $s$ and Expulsion Erugs $_{s}$ is the measure of penalty severity at school $s$ for students caught using an illegal drug at school for a second time (i.e., an indicator variable for whether the school expels second-time offenders). In all cases, the counterfactual to expulsion remains an out-of-school suspension and, as before, errors are corrected for clustering at the school level.

\footnotetext{
${ }^{8} \mathrm{As}$ an alternative, one could include fixed effects for each first-offence penalty and instrument for the variation in second-offence penalties. But, given that second-offence consequences are irrelevant for schools that already expel first-time offenders, such an approach would merely add the students from the four schools that issue in-school suspension. The results are not sensitive to their inclusion and are not reported.
} 


\subsubsection{The instruments}

As with drug-related occurrences, the School Administrator Questionnaire in the Add Health survey includes first- and second-occurrence penalties for a variety of other offences. Being careful to avoid employing instruments that themselves may influence drug use and can not be excluded from the second stage, I instrument for Expulsion drugs $_{s}$ with the difference in severity between the first and second penalties associated with other infractions. For example, with the information on penalties for infractions of type $j$ at school $s$, a potential instrument $Z_{s}^{j}$ can be defined as,

$$
Z_{s}^{j}=\text { SecondPenalty } y_{s}^{j}-\text { FirstPenalty }{ }_{s}^{j}
$$

Across $j$, this amounts to a set of school-specific "punishment trajectories" that are independent of level differences in penalty severity across schools. Below, I discuss the particular choice of infractions $j$, such that $Z_{s}^{j}$ are unlikely to relate to substance use itself.

In order to quantify penalties (and the differences between first and second penalties) I impose a cardinal ranking on the available penalties. Penalties can range from "verbal warning" to "expulsion," which I simply map onto the range one through five. ${ }^{9}$ As a result, the higher is a given $Z_{s}^{j}$ the more school $s$ tends to ramp up the severity across first and second offences of type $j$. For example, if school $m$ imposes an expulsion for a second offence but only an out-of-school suspension for a first offence, then $Z_{m}^{j}=5-4=1$, which would be equivalent to school $n$ imposing an out-of-school suspension for a second offence and an in-school suspension for a first offence, with $Z_{n}^{j}=4-3=1$. Quite clearly, $Z_{s}^{j}$ is independent of level differences in penalty severity across schools. ${ }^{10}$

Among the trajectories that are arguably excludable, I adopt two as instruments throughout the analysis - the difference between first- and second-offence punishments for "Stealing school property" and for "Verbally abusing a teacher." The trajectories derived from several other categories of infraction are not considered as possible instruments, as the exclusion restrictions in these cases seem problematic. In particular, those related directly to substance use are unlikely to satisfy the exclusion restriction. ${ }^{11}$ It is also questionable whether those associated with other risky behaviours are excludable. Since estimates are not qualitatively different if they are not included as instruments, I discard them from the estimating equations. ${ }^{12}$ The remaining contender, "Cheating," can likely be excluded from the drug

\footnotetext{
${ }^{9}$ The full set of possible penalties is, "(1) verbal warning," "(2) minor action," "(3) in-school suspension," "(4) out-of-school suspension," and "(5) expulsion." In reality, consequences need not span this entire range, however. For example, as suggested already, no school imposes less than an "in-school suspension" for drug offences.

${ }^{10}$ The benefit to identifying off of these trajectories is made all-the-more salient when considering the evidence offered by Babcock (2009), who suggests that high-school graduation and labor participation outcomes appear higher for students who attended schools with stricter discipline policies - notably, schools with higher average punishment levels over a range of disciplinary margins. Also identifying off of levels, Barton, Coley, and Welingsky (1998) find that stricter discipline policies in tenth grade to be associated with lower rates of delinquency in 12 th grade.

${ }^{11}$ These include smoking at school, drinking alcohol at school, possessing alcohol, and possessing an illegal drug.

${ }^{12}$ These included fighting with another student, injuring another student, possessing a weapon, and physically injuring a teacher.
} 
equation but does not survive redundancy tests and is therefore not included in the reported specifications. $^{13}$

Therefore, the identifying assumption is that conditional on being in a school that treats first-time drug offenders equivalently (using only the variation arising within grade levels and regions) one's marijuana use is not related to how much one's school increases it's penalty for stealing school property (or verbally abusing a teacher) between first and second occurrences. In Table 3, I report the estimated coefficients of a variety of school attributes regressed on each of the two instruments used below, and P-values associated with the null, $H_{0}: \hat{\beta}=0$. $\mathrm{I}$ also report $\mathrm{P}$-values for joint $F$ tests on the two instruments together predicting each of the attributes. In almost all cases, the trajectory implied by the school's treatment of first and second non-drug offences does not vary significantly with these observable attributes.

\subsubsection{The IV results}

In Column (1) of Table 4 I first report the OLS results from the sample of schools that penalize first-time offenders with out-of-school suspensions. As in Table 2, marijuana use does not appear to respond to whether these schools expel second-time offenders or issue a second out-of-school suspension. ${ }^{14}$ This estimate is, again, an upwardly biased estimate of the causal influence of expulsions to the extent that schools respond to drug use with stiffer penalties for second-time offenders, even when they share first-offence penalties.

IV estimates of the influence of second-offence expulsion on drug use are produced in Column (2). In short, correcting for the endogeneity of Expulsion reveals a very different relationship between school penalties and adolescent marijuana use. Within grade level and region, students attending schools that are equivalent with respect to their treatment of firsttime offenders but that penalize second occurrences with expulsion (instead of suspension) are significantly less likely to report that they consume marijuana. The estimated difference is also reasonably large, suggesting a .066 decrease in the probability that one has consumed marijuana in the thirty days prior to the survey where schools expel on second occurrences. At the mean usage of .15 this implies an impact of roughly 43 percent. The effect size in moving from out-of-school suspensions to expulsions is to reduce the proportion of students consuming marijuana by roughly .18 standard deviations. ${ }^{15}$

In Table 5, I repeat the analysis on the intensive margin, defining Marijuana as the number of times marijuana was used in the month prior to being interviewed and restricting the sample to include only those for which Marijuana $>0$. First, one will note that the anticipated bias correction is apparent when the IV estimates in Column (2) are compared to the OLS estimates in Column (1). Similar patterns also emerge in the IV estimate of Expulsion, with usage falling some 5.5 over a mean of 12.6 times (monthly), for an impact of roughly 43 percent and an effect size of roughly .14 standard deviations. Even though this

\footnotetext{
${ }^{13}$ Including a cheating trajectory as part of the set of instruments yields slightly higher point estimates on second-offence expulsion. See Breusch et al. (1999) for details on testing for instrument redundancy.

${ }^{14}$ In unreported results, restricting the sample to the four schools that issue in-school suspension to firsttime offenders suggests that the influence of "Expulsion at $2^{\text {nd" }}$ is a larger positive but, unlike other models, estimates for this sample of schools are imprecise and sensitive to specification.

${ }^{15}$ These results are qualitatively robust to a limited information maximum likelihood estimator (LIML), which can be more robust to the presence of weak instruments. That said, the reported specifications yield first-stage $F$ statistics that far exceed the weak ID test critical values of Stock and Yogo (2005).
} 
sample is restricted to students who report using marijuana within the last 30 days, these estimates are close to those found around the extensive margin of use, reported in Table 4. That said, the IV estimate is imprecise and it would be reasonable to conclude that the margin of importance is the extensive margin.

\section{Discussion}

\subsection{Falsification}

One may fear that expulsion regimes are merely identifying a "type" of student, as reflected in their marijuana use, but not an actual difference in drug behaviour in response to penalty severity. In Table 6, I consider a potential falsification of the main result by running a similar specification but replacing drug use with the student's academic performance. In Column (1), performance is measured as the grade-point average across the student's four most-recent classes in English or language arts, mathematics, history or social studies, and science. As suggested in the results, more-severe consequences for drug use are not predictive of lower student performance. That expulsions don't also predict grade-based performance suggests that the above analysis is not merely identifying a "type" of student more broadly.

As a second measure, I consider the student's performance on a variant of the Peabody Picture Vocabulary Test (PPVT) that is administered to all survey respondents. The primary advantage the PPVT has over grade-based performance is that the test scores are comparable across schools and grades in a way that grade-base performance measures may not be. Likewise, however, in results reported in Column (2) I find no systematic variation in PPVT with the severity of school-imposed penalties for drug use. That there are distinctly different movements in student drug use and student performance around the treatment variable yields additional support to a causal interpretation.

\subsection{Reported drug use}

While tempting to consider the point estimate as the underlying true causal effect of penalty severity on drug usage, one important caveat remains. Notably, one must bear in mind that the above analysis points to a causal response of reported drug use to a school-imposed deterrent. The point estimate may still reflect both actual reduced usage and reductions in one's proclivity to report actual use. This is particularly important in this context as both may respond to drug-related penalties.

For example, both usage and reporting may respond negatively to increases in penalty severity. That said, care was taken to elicit truthful responses to potentially sensitive areas of disclosure. For example, the drug-use measure used in the current analysis were collected via audio-enhanced, computer-assisted self-interviewing protocols (Audio-CASI). ${ }^{16}$

\footnotetext{
${ }^{16}$ Respondents answer the questions themselves, rather than telling the interviewer their answers. "When you get to the first question, the computer will read the question to you so that you can hear it through these headphones. It will also tell you what to do to enter your answer. We have made it very simple for you to use the computer. Let's take a look at how it works, by completing a couple of practice questions."
} 


\section{Conclusion}

The focus of this analysis is on the potential for school policy to influence a student's consumption of marijuana. I model students' marijuana usage as a function of the penalties that would be imposed by the students' schools on those caught consuming an illegal drug. Given the potential endogeneity of these penalties, however, I adopt an instrumental-variables strategy to retrieve an estimate of the causal influence of expulsion on consumption.

In the end, estimates imply that in moving from out-of-school suspensions to expulsions is to reduce the proportion of students reporting 30-day marijuana consumption by roughly .18 standard deviations, or a 43 percent decrease from the mean propensity to consume of .15. I thereby demonstrate the efficacy of school-imposed penalties as a deterrent to adolescent drug use - the first evidence of such efficacy. Given what the literature has documented regarding the consequences of drug use - especially that in younger individuals - this research suggests that school sanctions may have important long-run benefits. 


\section{References}

Anderson, D. M. (2009). Does information matter? The effect of the Meth Project on meth use among youths. Working paper, University of Washington.

Babcock, P. (2009). The rational adolescent: Discipline policies, lawsuits, and skill acquisition. Economics of Education Review 28(5), 551-560.

Barton, P., R. Coley, and H. Welingsky (1998). Order in the classroom: Violence, discipline and student achievement. Princeton, NJ: Policy Information Cetner, Educational Testing Service.

Bretteville-Jensen, A. L. and L. Jacobi (2008). Climbing the drug staircase: A Bayesian analysis of the initiation of hard drug use. Discussion Paper 3879, IZA Bonn.

Breusch, T., H. Qian, P. Schmidt, and D. Wyhowski (1999). Redundancy of moment conditions. Journal of Econometrics 91(1), 89-111.

Chatterji, P. (2006). Illicit drug use and educational attainment. Health Economics 15(5), 489-511.

Cook, P. J., D. C. Gottfredson, and C. Na (2009). School crime control and prevention. Technical report, Duke University.

DeSimone, J. (2002). Illegal drug use and employment. Journal of Labor Economics 20(4), 952-977.

Kaestner, R. (1995). The effects of cocaine and marijuana use on marriage and marital stability. NBER Working Papers 5038, National Bureau of Economic Research.

Markowitz, S. (2000). The role of alcohol and drug consumption in determining physical fights and weapon carrying by teenagers. NBER Working Papers 7500, National Bureau of Economic Research.

Markowitz, S., P. Chatterji, R. Kaestner, and D. Dave (2002). Substance use and suicidal behaviors among young adults. NBER Working Papers 8810, National Bureau of Economic Research.

Mehay, S. L. and R. L. Pacula (1999). The effectiveness of workplace drug prevention policies: Does 'zero tolerance' work? NBER Working Papers 7383, National Bureau of Economic Research.

Mocan, H. N. and E. Tekin (2005). Drug use and juvenile crime: Evidence from a panel of siblings and twins. In B. Lindgren and M. Grossman (Eds.), Economics of Substance Use: Individual Behavior, Social Interactions, Markets, and Politics, pp. 91-120. Amsterdam: Elsevier.

Mocan, H. N. and E. Tekin (2006). Guns and juvenile crime. Journal of Law and Economics 49, 507-531. 
Mocan, H. N. and E. Tekin (2010). Ugly criminals. Review of Economics and Statistics 92(1), $15-30$.

Pacula, R. L., M. Grossman, F. J. Chaloupka, P. M. O'Malley, L. Johnston, and M. C. Farrelly (2000). Marijuana and youth. NBER Working Papers 7703, National Bureau of Economic Research.

Pacula, R. L., B. Kilmer, M. Grossman, and F. J. Chaloupka (2007). Risks and prices: The role of user sanctions in marijuana markets. NBER Working Papers 13415, National Bureau of Economic Research.

Ringel, J. S., P. L. Ellickson, and R. L. Collins (2006). The relationship between high school marijuana use and annual earnings among young adult males. Contemporary Economic Policy 24(1), 52-63.

Stock, J. H. and M. Yogo (2005). Testing for weak instruments in linear IV regression. Identification and Inference for Econometric Models: Essays in Honor of Thomas Rothenberg. Cambridge University Press.

van Ours, J. C. (2006). Dynamics in the use of drugs. Health Economics 15(12), 1283-1294.

Yamada, T., M. Kendix, and T. Yamada (1998). The impact of alcohol consumption and marijuana use on high school graduation. Health Economics 5(1), 77-92. 
Table 1: Summary statistics

\begin{tabular}{lcc}
\hline & Mean & StdDev \\
\hline Used marijuana in last 30 days & 0.14 & 0.35 \\
Grade level & 9.72 & 1.63 \\
Male & 0.49 & 0.50 \\
Black & 0.23 & 0.42 \\
Hispanic/Latino & 0.18 & 0.38 \\
Asian/Pacific & 0.08 & 0.27 \\
Other Non-White & 0.01 & 0.11 \\
Parent Educ: High school & 0.25 & 0.43 \\
Parent Educ: Some college & 0.25 & 0.43 \\
Parent Educ: College & 0.12 & 0.32 \\
Parent Educ: Graduate & 0.08 & 0.27 \\
Weekly religious attendance & 0.39 & 0.49 \\
Unemployment rate, county & 0.07 & 0.02 \\
Proportion urban, county & 0.66 & 0.39 \\
School size: 401-1000 & 0.34 & 0.48 \\
School size: 1001-4000 & 0.52 & 0.50 \\
School area: Urban & 0.30 & 0.46 \\
School area: Suburban & 0.52 & 0.50 \\
School governance: Private & 1.07 & 0.26 \\
Juvenile Arrests per 100k, county & 341.9 & 155.5 \\
Arrests per crime, county & 0.21 & 0.08 \\
Median HH Income, county & 30288 & 7969 \\
Observations & \multicolumn{2}{c}{17,016} \\
\hline
\end{tabular}


Table 2: OLS estimates of the relationship between marijuana use and school-imposed penalties

\begin{tabular}{lccc}
\hline & $(1)$ & $(2)$ & $(3)$ \\
VARIABLES & All & All & All \\
schools & schools & schools \\
\hline \multirow{2}{*}{ Expulsion on 2nd occurrence } & 0.007 & & \\
& $(0.013)$ & & $(0.012$ \\
Expulsion on 1st occurrence & -0.012 & -0.007 & \\
& $(0.034)$ & $(0.031)$ & \\
Suspension on 1st occurrence & -0.031 & -0.028 & \\
& $(0.034)$ & $(0.032)$ & \\
Male & $0.033^{* * *}$ & $0.033^{* * *}$ & $0.033^{* * *}$ \\
& $(0.006)$ & $(0.006)$ & $(0.006)$ \\
Black & -0.003 & -0.003 & -0.005 \\
Hispanic/Latino & $(0.011)$ & $(0.011)$ & $(0.011)$ \\
& -0.008 & -0.008 & -0.011 \\
Asian/Pacific & $(0.011)$ & $(0.011)$ & $(0.012)$ \\
Other Non-White & $-0.089^{* * *}$ & $-0.089^{* * *}$ & $-0.090^{* * *}$ \\
& $(0.014)$ & $(0.013)$ & $(0.014)$ \\
& $-0.044^{*}$ & $-0.044^{*}$ & $-0.044^{*}$ \\
Observations & $(0.025)$ & $(0.025)$ & $(0.025)$ \\
Grade-level FE & & & \\
Region FE & 17,016 & 17,016 & 17,016 \\
Mean & yes & yes & yes \\
\hline & yes & yes & yes \\
& 0.142 & 0.142 & 0.142 \\
\hline
\end{tabular}

The dependent variable is equal to one where the student reports to have consumed marijuana "in the last 30 days." Reported coefficients are least-squares estimates. All specifications also include controls for school size (i.e., small, medium, large), governance (i.e., public or private), and urbanicity (i.e., urban, suburban, rural), county-level juvenile arrests per capita, arrests per crime, median household income, the proportion urban, proportion rural, and unemployment rate, individual level indicators for gender, race (i.e., black, Asian, Hispanic, other nonwhite), parent education (i.e., less-than high school, high school, some college, bachelor, graduate/professional), and religious participation (i.e., an indicator variable for weekly attendance). Standard errors (in parentheses) are corrected for clustering at the school level. ${ }^{* * *} \mathrm{p}<0.01,{ }^{* *} \mathrm{p}<0.05,{ }^{*} \mathrm{p}<0.1$. 
Table 3: Correlation of the instruments with mean school attributes

\begin{tabular}{l|cc|cc|c}
\hline & \multicolumn{2}{|c|}{$j=$ "Stealing school } & \multicolumn{2}{c|}{$\begin{array}{c}j=\text { "Verbally abusing } \\
\text { property" }\end{array}$} & $\begin{array}{c}\text { Joint- } \\
\text { a teacher" }\end{array}$ \\
Dependent variable & $Z_{s}^{j}$ coefficient & P-value & $Z_{s}^{j}$ coefficient & P-value & P-value \\
\hline Age & -0.141 & 0.605 & -0.111 & 0.621 & 0.798 \\
Proportion black & 0.019 & 0.761 & -0.046 & 0.359 & 0.602 \\
Proportion Hispanic/Latino & -0.014 & 0.773 & -0.014 & 0.732 & 0.915 \\
Proportion Asian/Pacific & -0.035 & 0.112 & 0.008 & 0.647 & 0.228 \\
Proportion other non-white & -0.003 & 0.401 & -0.000 & 0.977 & 0.703 \\
Parent: Proportion high school & 0.042 & 0.274 & -0.027 & 0.390 & 0.331 \\
Parent: Proportion some college & -0.013 & 0.657 & 0.009 & 0.709 & 0.826 \\
Parent: Proportion college & -0.017 & 0.287 & 0.031 & 0.016 & 0.020 \\
Parent: Proportion graduate & -0.021 & 0.220 & 0.004 & 0.775 & 0.428 \\
Weekly religious attendance & 0.043 & 0.275 & 0.016 & 0.624 & 0.519 \\
Unemployment rate, county & -0.002 & 0.628 & -0.009 & 0.019 & 0.063 \\
Proportion urban, county & -0.148 & 0.066 & -0.078 & 0.245 & 0.119 \\
School size: 401-1000 & 0.100 & 0.360 & -0.012 & 0.894 & 0.639 \\
School size: 1001-4000 & -0.108 & 0.317 & 0.011 & 0.902 & 0.590 \\
School area: Urban & -0.119 & 0.248 & -0.142 & 0.092 & 0.154 \\
School area: Suburban & 0.151 & 0.169 & 0.123 & 0.174 & 0.189 \\
School governance: Private & -0.072 & 0.149 & 0.005 & 0.907 & 0.340 \\
Juvenile arrests per 100k, county & -42.755 & 0.247 & -14.674 & 0.631 & 0.486 \\
Arrests per crime, county & 0.007 & 0.694 & -0.007 & 0.628 & 0.801 \\
Median HH income, county & -1943.061 & 0.241 & -539.977 & 0.694 & 0.490 \\
\hline
\end{tabular}

Each coefficient represents a separate specification regressing the attribute on the instrument. 
Table 4: IV estimates of the deterrent effect of expulsion on marijuana use

\begin{tabular}{lcc}
\hline & $(1)$ & $(2)$ \\
VARIABLES & OLS & IV \\
\hline \multirow{2}{*}{ Expulsion on 2nd occurrence } & 0.009 & $-0.066^{* *}$ \\
& $(0.015)$ & $(0.033)$ \\
Male & $0.036^{* * *}$ & $0.036^{* * *}$ \\
& $(0.008)$ & $(0.008)$ \\
Black & -0.004 & 0.007 \\
& $(0.014)$ & $(0.016)$ \\
Hispanic/Latino & -0.013 & -0.010 \\
& $(0.014)$ & $(0.015)$ \\
Asian/Pacific & $-0.101^{* * *}$ & $-0.101^{* * *}$ \\
& $(0.015)$ & $(0.011)$ \\
Other Non-White & $-0.075^{* * *}$ & $-0.075^{* * *}$ \\
& $(0.028)$ & $(0.027)$ \\
& & \\
Observations & 11,555 & 11,555 \\
Grade-level FE & yes & yes \\
Region FE & yes & yes \\
F (first-stage) & $\mathrm{n} / \mathrm{a}$ & 13.60 \\
Mean & 0.153 & 0.153 \\
Impact (\%) & 5.841 & -43.34 \\
Effect size & 0.0248 & -0.184 \\
\hline
\end{tabular}

The dependent variable is equal to one where the student reports to have consumed marijuana "in the last 30 days." Reported coefficients are least-squares estimates. All specifications also include controls for school size (i.e., small, medium, large), governance (i.e., public or private), and urbanicity (i.e., urban, suburban, rural), county-level juvenile arrests per capita, arrests per crime, median household income, the proportion urban, proportion rural, and unemployment rate, individual level indicators for gender, race (i.e., black, Asian, Hispanic, other nonwhite), parent education (i.e., less-than high school, high school, some college, bachelor, graduate/professional), and religious participation (i.e., an indicator variable for weekly attendance). Standard errors (in parentheses) are corrected for clustering at the school level. ${ }^{* * *} \mathrm{p}<0.01,{ }^{* *} \mathrm{p}<0.05,{ }^{*} \mathrm{p}<0.1$. 
Table 5: Does the penalty for using illegal drugs influence the intensive margin?

\begin{tabular}{lcc}
\hline & $(1)$ & $(2)$ \\
VARIABLES & OLS & IV \\
\hline \multirow{2}{*}{ Expulsion on 2nd occurrence } & -1.693 & -5.456 \\
& $(2.530)$ & $(3.743)$ \\
& & \\
Observations & 1,769 & 1,769 \\
Grade-level FE & yes & yes \\
Region FE & yes & yes \\
F (first-stage) & n/a & 13.01 \\
Mean & 12.57 & 12.57 \\
Impact (\%) & -13.47 & -43.41 \\
Effect size & -0.0439 & -0.141 \\
\hline
\end{tabular}

The dependent variable is equal to the number of times the student reports to have consumed marijuana "in the last 30 days," conditional on consumption greater than zero. Reported coefficients are least-squares estimates. All specifications also include controls for school size (i.e., small, medium, large), governance (i.e., public or private), and urbanicity (i.e., urban, suburban, rural), county-level juvenile arrests per capita, arrests per crime, median household income, the proportion urban, proportion rural, and unemployment rate, individual level indicators for gender, race (i.e., black, Asian, Hispanic, other nonwhite), parent education (i.e., less-than high school, high school, some college, bachelor, graduate/professional), and religious participation (i.e., an indicator for weekly attendance). Standard errors (in parentheses) are corrected for clustering at the school level. ${ }^{* * *} \mathrm{p}<0.01,{ }^{* *} \mathrm{p}<0.05,{ }^{*} \mathrm{p}<0.1$. 
Table 6: Falsification exercises, using specification of Table 4(2)

\begin{tabular}{lcc}
\hline & $(1)$ & $(2)$ \\
VARIABLES & GPA & PPVT \\
\hline & & \\
Expulsion on 2nd occurrence & 0.208 & 6.289 \\
& $(0.139)$ & $(5.412)$ \\
& & \\
Observations & 11424 & 11058 \\
Grade-level FE & yes & yes \\
Region FE & yes & yes \\
Mean & 2.567 & 48.40 \\
\hline
\end{tabular}

The dependent variable in Column (1) is the grade-point average in the four most recent classes. The dependent variable in Column (2) is the student's score on the PPVT. Reported coefficients are least-squares estimates. All specifications also include controls for school size (i.e., small, medium, large), governance (i.e., public or private), and urbanicity (i.e., urban, suburban, rural), countylevel juvenile arrests per capita, arrests per crime, median household income, the proportion urban, proportion rural, and unemployment rate, individual level indicators for gender, race (i.e., black, Asian, Hispanic, other nonwhite), parent education (i.e., less-than high school, high school, some college, bachelor, graduate/professional), and religious participation (i.e., an indicator for weekly attendance). Standard errors (in parentheses) are corrected for clustering at the school level. *** $\mathrm{p}<0.01, * * \mathrm{p}<0.05, * \mathrm{p}<0.1$. 